\title{
金融危机背景下珠三角产业演化模式及机制研究 基于行业空间网络的视角
}

\author{
李珊, 宋雨儒, 秦小珍, 许伟攀, 李 那* \\ (中山大学 地理科学与规划学院/中国区域协调发展与乡村建设研究院/城市化研究院,广州 510275)
}

\begin{abstract}
摘 要: 2008 年金融危机对全球制造业尤其是“世界加工厂”珠三角地区的产业链生态空间产生了较大影响, 高质 量的市场需求、弹性生产模式等冲击了珠三角传统生产模式。大规模生产企业的倒闭, 影响了珠三角地区产业集 群之间的联系。论文基于演化经济地理学下的复杂网络视角,利用 2008年全国第二次经济普查与 2013年全国第 三次经济普查数据库, 在镇街空间尺度上科学构建了广东省制造业行业空间网络, 对珠三角 5 大主导行业组团的 内外联系进行了分析, 并探讨了珠三角地区镇街尺度上产业空间演化模式, 最后以佛山市北浫镇为案例进行了实 证。研究发现,珠三角在行业空间网络上体现为主导行业组团内部产业关联度增加、主导行业组团之间的产业关 联度降低, 反映出为增强地区韧性、适应全球市场的新需求, 地区开始跳出本地配套支撑, 融入外部生产市场, 从相 对初级、多元化的分散化发展演化为高端、专业化的集中式发展的产业空间生态模式。未来, 珠三角亟需转型, 为 更快速响应全球市场, 建议地区不止于为发达国家提供加工制造, 应做强本地特色化的生产品牌, 构建本地的完整 产业链条, 以谋求可持续化的产业发展。
\end{abstract}

关 键 词: 金融危机背景; 行业空间网络; 产业联系; 演化; 珠三角

产业联系能影响地区产业结构演化, 厘清产业 联系能为地区未来发展提供战略性参考, 学界相关 研究由来已久吕。“全球一地方”对话下的产业组织 理论强调对经济宏观环境的关注 ${ }^{[2]}$ 。随着生产过程 的切割和不同空间中企业的紧密生产合作,全球生 产网络通过离岸外包机制, 借由产业链的传导对世 界经济体间的产业联系产生影响。2008年金融危 机重创全球经济格局 ${ }^{[3]}$, 极大地冲击了不同空间尺 度下的区域产业联系。作为地区生产网络演化原动 力的企业 ${ }^{[4-5]}$, 在金融危机下会选择怎样的发展策略 与发展路径, 地区又将如何转型? 为应对不确定的 全球经济环境,地区是倾向于选择专业集中式发展, 以在产业链和贸易格局中占据高地, 还是倾向选择 多元分散式发展形成相对多元的产业簇群, 以扁平
化形态应对经济市场? 这是一个值得研究的话题。

珠三角作为中国改革开放先锋,已深嵌于全球 贸易体系, 区域内大量乡镇企业承担国际发达国家 的外包、组装与初级加工制造, 在镇街形成了各具 比较优势的主导产业 ${ }^{[6]}$, 构建了产业间紧密联系的 本地生产网络,催生出极具生命力的产业集群,一度 成为举世闻名的“世界工厂”。因此, 研究金融危机 背景下珠三角地区生产网络的演化模式, 对于理解 全球化下中国在区域尺度上的产业发展路径颇具意 义, 能为地方政府制定发展政策提供一定的参考。

\section{1 产业联系理论与假设提出}

20 世纪初,许多学者以产业集群、产业区的理

收稿日期:2020-06-19; 修订日期: 2020-08-16。

基金项目: 国家自然科学基金项目(41971157)。[Foundation: National Natural Science Foundation of China, No. 41971157. ]

第一作者简介:李珊(1987-),女, 湖北天门人,博士生, 主要研究方向为城市与区域发展、产业发展等。

E-mail: lishan8@mail2.sysu.edu.cn

*通信作者简介:李邭(1964-), 男, 江西南昌人,教授,博导, 主要从事经济地理、城市与区域规划等方面研究。

E-mail: lixun@mail.sysu.edu.cn

引用格式: 李珊, 宋雨儒, 秦小珍, 等. 金融危机背景下珠三角产业演化模式及机制研究: 基于行业空间网络的视角 [J]. 地理科学进展, 2021, 40(4): 635-646. [Li Shan, Song Yuru, Qin Xiaozhen, et al. Study on the industrial evolution pattern and mechanism of the Pearl River Delta under the background of financial crisis: Based on the perspective of industry space network. Progress in Geography, 2021, 40(4): 635-646. ] DOI: 10.18306/dlkxjz.2021.04.008 
念研究具有相互联系的企业的集聚现象 ${ }^{[7-8]}$ 。新产 业区理论认为, 企业通过隐性知识传递建立紧密的 本地产业联系 ${ }^{[9]}$, 呈现出产业集聚模式。到 20 世纪 中后期, 全球化快速发展导致各地的生产联系产生 重大变革,使得全球生产网络受到广泛的关注, 目的 在于了解不同地理空间中生产功能的联系 ${ }^{[10-11]}$ 。跨 国企业为了降低成本向外寻找新的生产合作场所, 生产活动开始打破地理界线, 重构地区与外界的产 业联系 ${ }^{[12-13]}$ 。地区产业联系是一个动态的过程, 近 年来演化经济地理学下产品空间理论 (product space $)^{[14]}$ 的兴起, 为探讨产业联系演化提供了新视 角 ${ }^{[15-19]}$ 。路径依赖力量促进地区原有企业在历史制 度环境、要素禀赋等环境中形成了根植于本地的生 产网络 ${ }^{[15,20-23]}$, 产业发展会沿着原有路径发展; 而外 部冲击作为 “变异”因素, 会影响企业的市场选择与 战略决策, 能为本地带来危机或转机。把握 “机会 窗口”, 地方就能改变原有路径, 催生地区产业关联 发生改变 ${ }^{[24-28]}$, 重塑本地的经济产业格局与演化路 径 ${ }^{[18,29-32]}$ 。关于产业联系的测度, 产品空间理论认为 不同产业对生产性要素如土地、气候、劳动力与技 术等的要求越相似,产业之间邻近性或联系程度越 高 ${ }^{[1,33]}$, 因此构建了一种不同于传统计算产业联系 的投人一产出、直接消耗系数 ${ }^{[34-35]}$ 等的新颖方法, 是 以结果导向对复杂生产网络中各产业之间的综合 邻近性进行度量, 现被学界广泛应用 ${ }^{[14,36-37]}$ 。

然而, 既有理论和实证研究大多从行业整体层 面分析产业联系, 较少对产业内与产业间的联系进 行区分, 但我们认为地区生产网络错综复杂, 上下 游产业与支撑配套产业对本地产业的发展产生的 影响程度不同, 对地区产业内关联与产业间关联予 以区别分析 ${ }^{[38]}$, 更有助于刻画地区产业发展的演化 路径与空间特征 ${ }^{[1,39]}$ 。

金融危机背景下, 珠三角大量规模小、抗风险 能力弱的中小配套企业倒闭 ${ }^{[40]}$, 引发了珠三角本地 生产供应链断裂、无法再实时响应市场需求。为即 时弥补生产断链的危机, 珠三角的企业采取应对危 机的发展策略, 极大地影响了其生产网络的产业联 系。第一, 由于本地配套企业韧性不足、无法满足 弹性生产模式下市场对产品的高质量要求, 主导企 业开始跳出本地生产网络 ${ }^{[4]}$, 转向外部周边镇街或 其他地区寻求支撑, 强化了不同地域产业之间的 联系。第二, 大型企业自身选择垂直整合的生产 模式 ${ }^{[41]}$, 尝试将对外采购的产业支撑模块纳人生产
线,减少对外部供应商的配套服务需求与生产依 赖, 增强了企业所在区域产业内的生产联系。另 外, 路径依赖下地区主导产业会在本地衍生出与具 有相似劳动力、资本、技术和制度需求的行业内关 联企业, 发展为更具凝聚力、更具韧性的地区生产 网络 ${ }^{[2]}$ 。地方政府作为看得见的手,会制定政策介 人地方的产业发展,维护保障地区主导产业对当地 产生的社会经济效益。珠三角生产网络内, 既存在 促进产业紧密联系的凝聚力, 又存在推动产业联系 分散的离心力(图 1)。

金融危机背景下, 珠三角区域的生产网络中产 业内外联系的演化模式如何? 本文基于上述分析提 出 2 个假设:

（1）假设 1 : 当地主导企业突破地理边界, 与本 地其他行业配套企业联系弱化，不同行业间的产业 关联降低,不同镇街的产业集群之间形成差异化的 产业生态 ${ }^{[4,42]}$ 。

（2）假设 2 : 本地同一产业内的企业关联会增 强, 在空间尺度上将表现为本地镇街产业集群向着 高端专业化的集中式发展。

\section{2 数据与方法}

本文所用数据来源于 2008 年第二次广东省经 济普查数据和 2013 年第三次广东省经济普查数据 库。2008年金融危机的发生直接对企业产生冲击， 受冲击的前 $5 \mathrm{a}$ 是影响企业生存与发展的最关键时 期, 企业经历过重大波动后将逐渐走向稳定, 因此, 用2008、2013 年的数据能直接分析金融危机背景下 企业为主体导致的产业模式变化。这 2 次经济普查 数据库涵盖了广东省所有企业的相关信息,包括企 业名称、企业编码、行业代码、从业人数、营业收人 等属性。

基于 $\mathrm{R}$ 软件, 本文参考 Hidalgo 等 ${ }^{[14]}$ 构建产品空 间网络的方法,构建广东省的行业空间网络(industry space)。构建行业空间网络的核心指标是产业 比较优势(RCA)和产业之间的邻近度(Proximity)。 比较优势 RCA 用某地区某产业从业人口数量相对 于整体区域的相对比重来衡量, 当 RCA $>1$ 时, 表明 该地区该产业发展具有比较优势; 邻近度 Proximity 表示产业联系,采用某地区 2 个产业的从业人口在 同一地区都具有比较优势的条件概率最小值来测 度, 若该条件概率越大, 表明这 2 个产业之间邻近度 


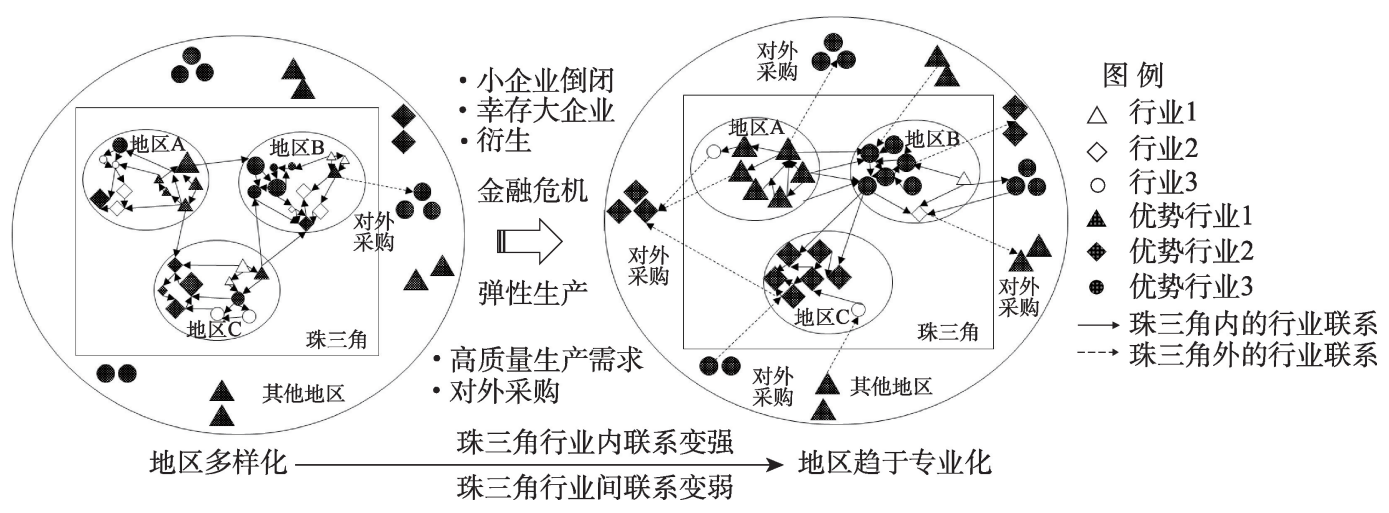

注:图中行业图形的大小表示对应行业的优势程度大小。

图 1 金融危机背景下珠三角产业生态空间发展演化模式

Fig.1 Change of industrial ecology in the Pearl River Delta under the background of financial crisis

越大,两者联系就越紧密。具体计算公式如下：

$$
\begin{gathered}
\mathrm{RCA}_{c, i}=\frac{x(c, i)}{\sum_{i} x(c, i)} / \frac{\sum_{c} x(c, i)}{\sum_{c, i} x(c, i)} \\
\phi_{i, j}=\min \left\{P\left(\operatorname{RCA}_{x_{i}} \mid \mathrm{RCA}_{x}\right), P\left(\mathrm{RCA}_{x} \mid \mathrm{RCA}_{x_{i}}\right)\right\}
\end{gathered}
$$

式中: $x(c, i)$ 为 $c$ 地区 $i$ 产业从业人口数; $\mathrm{RCA}_{c, i}$ 为 $c$ 地区 $i$ 产业的比较优势; $P\left(\mathrm{RCA}_{x_{i}} \mid \mathrm{RCA}_{x_{j}}\right)$ 表示所有 地区中 $j$ 产业具有比较优势时 $i$ 产业也具有比较优 势的条件概率; $\phi_{i, j}$ 为邻近度, 取值在 $0 \sim 1$ 之间。

构建行业空间复杂网络主要分为 3 大步骤, 以 2013 年广东省制造业网络为例: 第一步,计算出广 东省 479 个制造业从业人口在所有 1688 个镇街单 元上的 $479 \times 1688$ 比较优势矩阵 $\boldsymbol{A}$; 第二步, 以比较 优势矩阵 $\boldsymbol{A}$ 为基础,计算广东省任意 2 个制造业同 时具有比较优势的条件概率最小值, 形成行业 $479 \times$ 479 的邻近性矩阵 $\boldsymbol{B}$; 最后, 根据邻近性矩阵 $\boldsymbol{B}$, 结合 “最大生成树” 算法 ${ }^{(1)}$, 采用 “力导引”布局 ${ }^{(2)}$, 构建出 制造业行业空间网络。

\section{3 广东省制造业行业空间网络的构建}

珠三角劳动力丰富、开发成本低廉、基础设施 发达, 拥有国际港口和国际机场, 共同构成了强大 的制造业生态系统优势, 是广东省制造业的支柱。 本文以 2008 年和 2013 年全国第二次、第三次经济
普查中的广东省企业数据为基础,构建金融危机前 后广东省制造业行业空间网络。由图 2 和图 3 可 见, 行业空间网络包括电气机械及器材、通信电子 设备、金属制品、纺织服装与交通运输设备 5 大主导 产业组团。这 5 大产业组团高度集聚在珠三角。珠 三角人口总规模约占广东省的 $86 \%$, 其中电气机械 及器材、通信电子设备占比的人口规模占比更是超 过 $90 \%$ 。因此,基于广东省行业空间网络能很好地 对珠三角的产业模式演化进行研究。

(1) 通信电子设备行业组团, 是主导行业中位 于网络最核心的行业。这反映该产业对其他产业 的整体带动性最强。该组团与电气机械及器材制 造组才紧密关联;

(2) 电气机械及器材制造组团, 在产业网络中 的核心度仅次于通信电子设备行业,该组团横亘网 络,连接产业网络的核心区域与外围地带, 是网络 中链条最长的行业组团, 与通信电子设备行业共同 构成核心集群;

(3) 金属制品组团,集中位于行业空间网络下 部的外围地带, 与印刷媒介、纺织服装、通用设备、 电气机械与通信电子设备等诸多行业都存在一定 关联;

(4) 纺织服装组团, 主要分布于行业空间网络 下部的外围地带, 周边关联性行业单一,与金属制 品的产业联系相对明显;

(5) 交通运输设备组团,在产业网络的核心度最

(1) 最大生成树的原理是以权重为导向, 生成产品空间网络的框架, 如果有 $N$ 个节点(节点表示产品, $N$ 表示产品的数量), 则生成 $N-1$ 条节点连 接线(连接线的值表示邻近度大小),保证网络整体的邻近度总和最大。

(2) 力导引布局是一种较佳的可视化网络布局算法, 将节点视作电荷粒子, 连杆为弹簧, 通过模拟电荷间相互作用力得到节点之间的距离, 最 终达到一个稳定平衡的布局状态。 


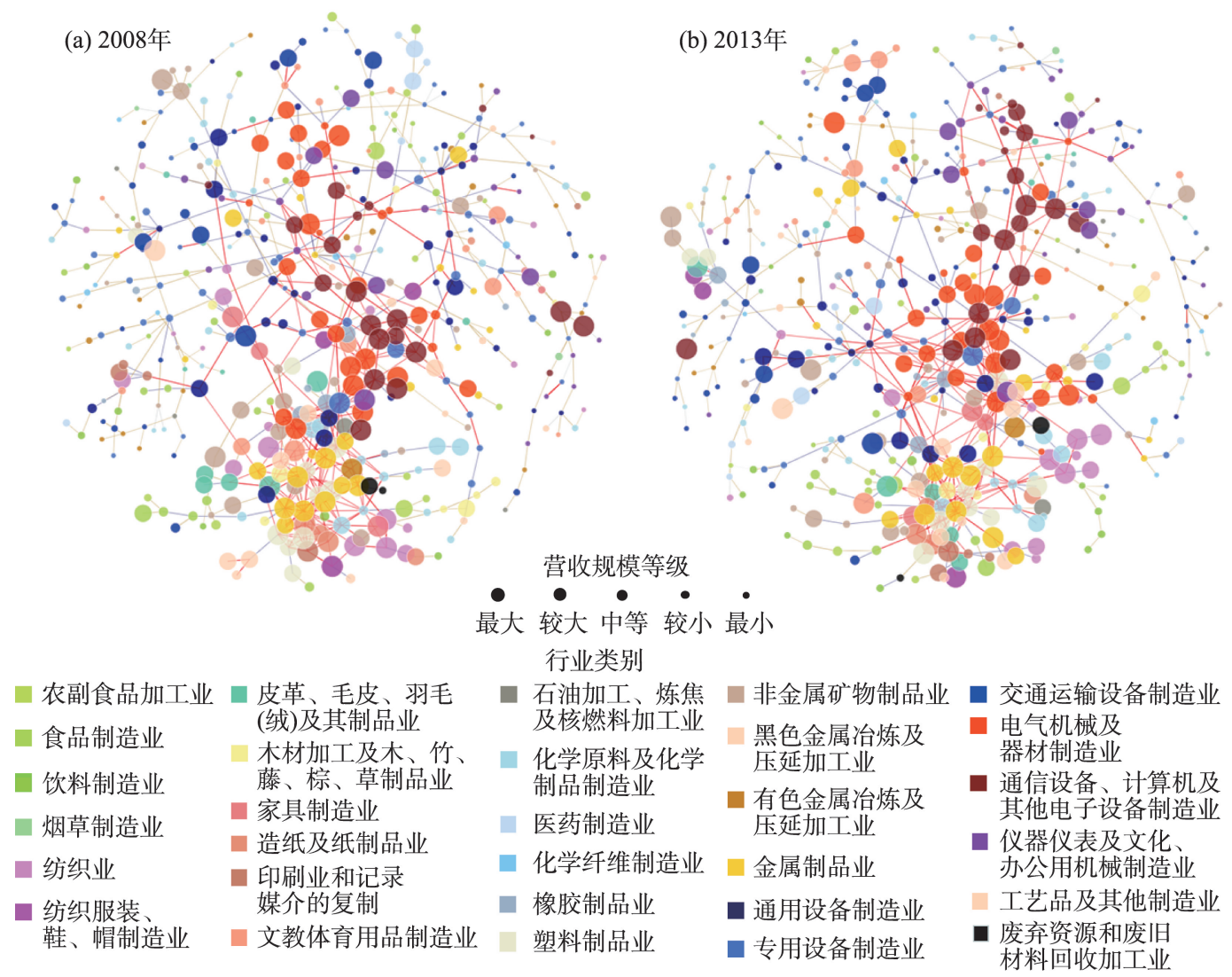

图 22008 年和 2013 年广东省制造业行业空间网络

Fig.2 Manufacturing industry space of Guangdong Province, 2008 and 2013

(a) 2008年

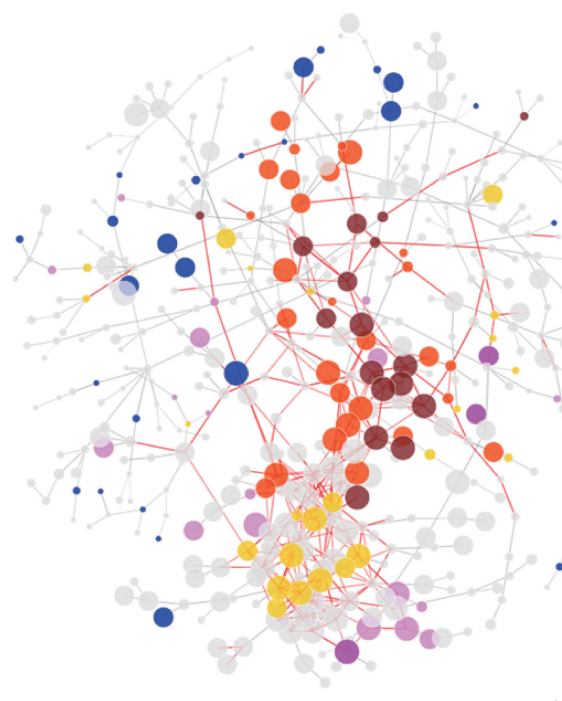

(b) 2013 年

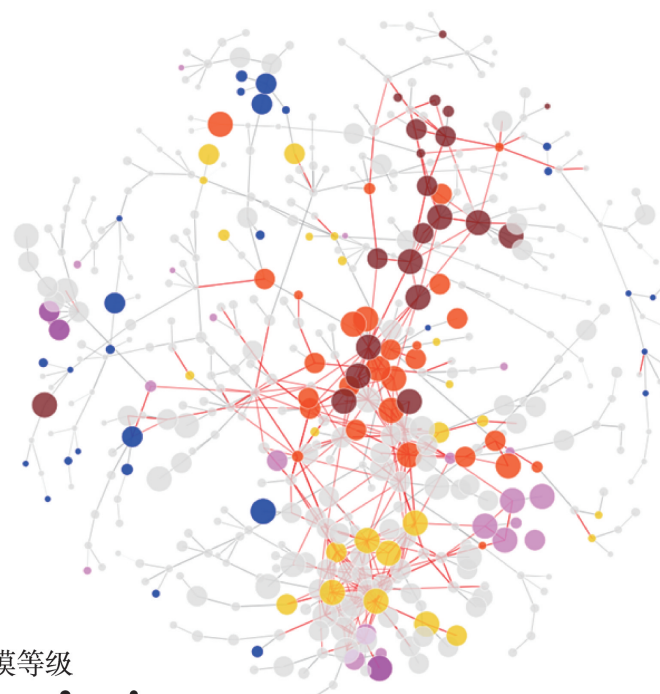

最大 较大 中等 较小最小

\begin{tabular}{|c|c|c|c|c|c|}
\hline & 组团1 & 组团 2 & 组团3 & 组团4 & 组团 5 \\
\hline 米 & $\begin{array}{l}\text { 纺织服装、 } \\
\text { 鞋、帽制造 }\end{array}$ & 金螷制品业 & $\begin{array}{l}\text { 父通运输㱼备 } \\
\text { 制造业. }\end{array}$ & 及器材制造业 & $\begin{array}{l}\text { 通信㱼备、谓萛仙及 } \\
\text { 其他电子设备制造业 }\end{array}$ \\
\hline
\end{tabular}

图 3 主导行业组团在广东省制造业行业空间网络中的位置

Fig.3 Location of leading industrial groups in the manufacturing industry space of Guangdong Province 
低, 分散分布在产业网络的外围, 与其他主导组团之 间的产业联系弱,组团内部的产业联系也不强。

金融危机后, 2013 年与 2008 年制造业产业空 间网络的主导行业基本一致, 仍以电气机械及器 材、通信电子设备、金属制品、纺织服装与交通运输 设备为主导行业组团,但仪器办公机械作为珠三角 的新兴优势行业开始涌现。同时我们发现, 这 5 大 主导行业在网络中的空间布局发生了较为明显的 变化。电气机械及器材行业组团内部联系更凝聚, 通信电子设备与电气机械及器材行业发展态势恰 好相反。

整体上看, 制造业产业空间网络从2008年一个 紧密联系的带状大簇群, 过渡到 2013 年的 3 个逐渐 分离的小簇群: 黄色的金属制品与纺织服装组团簇 群、深红色的电气机械及器材组团簇群、暗红色的 通信设备和仪器办公机械行业组团簇群。

\section{4 珠三角行业关联度的测度与演化}

\section{1 行业间产业联系演化}

从 2008 年和 2013 年广东省行业空间网络看 出, 主导组团间呈现分离态势, 这直观地反映了珠 三角制造业优势产业之间的关联性降低。下文将 通过科学的量化方法予以分析。

(1) 选取测度行业间关联性的代表行业集合。 本文基于 $\mathrm{R}$ 软件, 将电气机械及器材、通信电子设 备、金属制品、纺织服装与交通运输设备这 5 大行业 的行业小类(四位编码)按照行业劳动力规模进行位 序排列。为避免 5 大簇群内非主导行业间的邻近性 对簇群间关联性形成偏差, 选取行业劳动力规模前 $10 \%$ 的小类行业构成绝对主导行业集合 $C$, 并将 $C$ 集合中属于电气机械及器材的行业小类抽取形成 子集 $C_{1}$, 属于通信电子设备电气机械及器材的行业 小类抽取形成子集 $C_{2}$, 属于金属制品的行业小类抽 取形成子集 $C_{3}$, 属于纺织服装的行业小类抽取形成
子集 $C_{4}$, 属于交通运输设备的行业小类抽取形成子 集 $C_{5}$ 。

(2) 计算不同主导组团内产业之间的关联性。 以广东省任意 2 个制造业同时具有比较优势的条件 概率最小值计算的邻近性矩阵 $\boldsymbol{B}$ 为基础, 选取 $C_{1}$ 、 $C_{2} 、 C_{3} 、 C_{4} 、 C_{5}$ 中的任意 2 个子集,构建一个子集内任 意行业与另一子集内任意行业之间的关联性矩阵, 以这一关联性矩阵的均值作为这 2 个行业之间的关 联性。以计算电气机械及器材和通信电子设备之 间的关联性为例: 电气机械及器材子集 $C_{1}$ 包含 $\left\{p_{1}\right.$, $\left.p_{2}, \cdots, p_{M}\right\}$ 共 $M$ 个行业小类, 通信电子设备子集 $C_{2}$ 包含 $\left\{q_{1}, q_{2}, \cdots, q_{N}\right\} N$ 个行业小类, 则 $C_{1}$ 行业与 $C_{2}$ 行 业之间的邻近度：

$$
\phi_{C_{1} C_{2}}=\frac{\sum_{i, j} \phi_{C_{1} p_{i} C_{2} q_{j}}}{M \times N}(i=1,2, \cdots, M ; j=1,2, \cdots, N)
$$

以此类推, 分别计算 5 大行业组团之间的相互 关联性。

2008 年广东省制造业行业空间网络中,金属制 品业、交通运输设备业与其他产业具有强关联性, 通信电子设备与其他产业关联性弱(表 1$)$ 。金属制 品能为众多产业提供零配件, 是珠三角生产系统中 必不可少的中间环节。交通运输设备业则能为珠 三角制造业提供强有力的物流支撑。通信电子设 备包括计算机与电子信息类制造等细分产业,属于 高新技术密集型, 具有一定的技术门槛, 与其他行 业之间的关联性不高, 更多体现在产业内的关联。 分行业看, 5 大主导组团中纺织服装与金属制品、金 属制品与交通运输设备、交通运输设备与金属制 品、电气机械及器材与金属制品、通信电子设备与 电气机械及器材的产业关联性最大。具体而言, 纺 织服装业内的纺织机器、纽扣拉链配饰等都属于金 属制品,故纺织服装与金属行业关联性最大; 金属 制品中大量钢铁铝材, 用作各种交通运输设备制造 如汽车、铁路动车与船舶制造等的主材料, 所以两 者联系紧密; 电气机械及器材业的各类元件制造与

表 12008 年主导产业组团之间的产业联系

Tab.1 Proximity of leading industrial groups, 2008

\begin{tabular}{|c|c|c|c|c|c|c|}
\hline 产业 & 纺织服装 & 金属制品 & 交通运输设备 & 电气机械及器材 & 通信电子设备 & 均值 \\
\hline 纺织服装 & 1.000 & 0.196 & 0.167 & 0.123 & 0.089 & 0.144 \\
\hline 金属制品 & 0.196 & 1.000 & 0.217 & 0.181 & 0.122 & 0.179 \\
\hline 交通运输设备 & 0.167 & 0.217 & 1.000 & 0.166 & 0.129 & 0.170 \\
\hline 电气机械及器材 & 0.123 & 0.181 & 0.166 & 1.000 & 0.159 & 0.157 \\
\hline 通信电子设备 & 0.089 & 0.122 & 0.129 & 0.159 & 1.000 & 0.125 \\
\hline
\end{tabular}


金属制品密不可分, 这 2 大产业的关联性也大; 通信 电子设备业的计算机、集成电路设备、印制电路板 等, 需要配套的电力电子元器件组装, 故通信电子 设备与电气机械及器材的关联性大。

2013 年制造业主导产业之间的关联性与 2008 年基本保持一致，仍是金属制品与其他行业间之间 关联性最大, 通信电子设备与其他行业间关联性最 小(表 2)。分行业看, 5 大产业各自对应的最关联行 业与 2008 年一致: 纺织服装与金属制品、金属制品 与交通运输设备、交通运输设备与金属制品、电气 机械及器材与金属制品、通信电子设备与电气机械 及器材两两之间的关联性最大。

由表 3 看出,珠三角各主导行业之间的整体关 联性几乎都呈减弱趋势。具体来说, 纺织服装与其 他产业之间的平均关联度下降 $9.0 \%$, 电气机械及器 材与其他产业间的平均关联度下降 5.7\%, 通信电子 设备与其他产业间平均关联度下降 $4.8 \%$, 金属制品 与其他产业间平均关联度下降 $3.9 \%$, 交通运输设备 与其他产业间平均关联度下降 $3.5 \%$ 。其中, 纺织服 装与电气机械及器材业、交通运输设备业的关联度 降低最为显著, 分别降低 $13.0 \% 、 10.2 \%$ 。

上述研究结论充分验证了本文提出的假设 1 : 珠三角行业间的产业联系变弱。

\section{2 行业内产业联系演化}

为弄清珠三角产业组团内的关联性如何演化 呢, 下文将以主导产业为例, 研究地区生产网络行 业内关联变化, 具体通过各组团内产业小类的平均
邻近性来衡量产业内关联性。

由表 4 可以看出, 2008 年珠三角主导产业组团 内关联度最大的是金属制品和通信电子设备业, 产 业内关联最低的是交通运输设备业。相对于 2008 年, 2013 年珠三角各主导组团产业内关联性的相 对大小保持不变, 仍是金属制品和通信电子设备 的产业内关联最大, 交通运输设备业的产业内关 联最小。

2013 年, 5 大主导产业组团内关联性均呈增强 趋势。其中, 纺织服装产业内关联性增强最为明 显, 高达 $20.12 \%$, 交通运输设备产业内关联增强 $5.81 \%$, 金属制品、通信电子设备和电气机械及器材 的产业内关联也呈增强态势。珠三角镇街的专业 化特色更为明显, 为增强应对外来冲击的韧性, 市场 导向下各镇街都充分发挥本地比较优势, 基于根植 于本地的生产网络衍生出产业内邻近性更强的企 业,使得地区同一产业内的上下游企业更加活跃。 这充分验证了假设 2 : 珠三角行业内的产业联系 增强。

通过构建行业空间网络下行业间与行业内产 业联系的量化测度方法,本文确实发现了珠三角生 产网络中存在行业间产业联系减弱、行业内的产业 联系增强的事实。那么, 影响行业内外产业联系演 化的背后机制究竟是什么? 地区产业演化和微观 企业选择密不可分,因此,进一步以珠三角典型专 业镇为案例, 试图阐释珠三角行业空间网络演化的 变迁过程。

表 22013 年主导产业组团之间的产业联系

Tab.2 Proximity of leading industrial groups, 2013

\begin{tabular}{|c|c|c|c|c|c|c|}
\hline 产业 & 纺织服装 & 金属制品 & 交通运输设备 & 电气机械及器材 & 通信电子设备 & 均值 \\
\hline 纺织服装 & 1.000 & 0.188 & 0.150 & 0.107 & 0.081 & 0.131 \\
\hline 金属制品 & 0.188 & 1.000 & 0.223 & 0.167 & 0.111 & 0.172 \\
\hline 交通运输设备 & 0.150 & 0.223 & 1.000 & 0.158 & 0.125 & 0.164 \\
\hline 电气机械及器材 & 0.107 & 0.167 & 0.158 & 1.000 & 0.161 & 0.148 \\
\hline 通信电子设备 & 0.081 & 0.111 & 0.125 & 0.161 & 1.000 & 0.119 \\
\hline
\end{tabular}

表 3 区域主导产业间的关联性演化

Tab.3 Regional proximity change of leading industrial groups

(\%)

\begin{tabular}{|c|c|c|c|c|c|c|}
\hline 产业 & 纺织服装 & 金属制品 & 交通运输设备 & 电气机械及器材 & 通信电子设备 & 演化均值 \\
\hline 纺织服装 & 0 & -4.1 & -10.2 & -13.0 & -9.0 & -9.0 \\
\hline 金属制品 & -4.1 & 0 & 2.8 & -7.7 & -9.0 & -3.9 \\
\hline 交通运输设备 & -10.2 & 2.8 & 0 & -4.8 & -3.1 & -3.5 \\
\hline 电气机械及器材 & -13.0 & -7.7 & -4.8 & 0 & 1.3 & -5.7 \\
\hline 通信电子设备 & -9.0 & -9.0 & -3.1 & 1.3 & 0 & -4.8 \\
\hline
\end{tabular}


表4 区域主导产业内的关联性演化

Tab.4 Change of regional proximity within leading industrial groups

\begin{tabular}{lccc}
\hline \multicolumn{1}{c}{ 产业 } & $\begin{array}{c}2008 \text { 年产业 } \\
\text { 内关联 }\end{array}$ & $\begin{array}{c}2013 \text { 年产业 } \\
\text { 内关联 }\end{array}$ & 演化程度 $/ \%$ \\
\hline 纺织服装 & 0.164 & 0.197 & 20.12 \\
金属制品 & 0.234 & 0.239 & 2.14 \\
交通运输设备 & 0.086 & 0.091 & 5.81 \\
电气机械及器材 & 0.170 & 0.171 & 0.59 \\
通信电子设备 & 0.209 & 0.214 & 2.39 \\
\hline
\end{tabular}

\section{5 案例分析: 以佛山市北浫镇家电制 造行业为例}

本文以珠三角西岸佛山市顺德区北浫镇为例, 探讨金融危机背景下珠三角镇街的产业空间演化 模式。北深镇是中国家电制造业重镇、广东省示范 创新专业镇, 地区共集聚了 3000 多家家电整机及上 游配件企业, 家电巨头企业一一美的集团也坐落于 此, 地区每年约创造广东家电行业产值的 30\%、全 国家电行业产值的 $15 \%$, 多年位列中国百强乡镇前 列。北深镇是珠三角千亿制造强镇, 作为专业镇经 济发展良好的典型代表, 以其为案例对象, 有助于 对珠三角从微观个体企业层面、空间尺度地区层面 的双重维度研究和理解后金融危机背景下的产业 空间联系演化模式。

\section{1 产业集群演化模式: 从扁平多样的分散式发展 走向高端专业化的集中式发展}

2008 年, 北浫镇制造业大部分处于产业链的低 端, 企业利润被挤压, 地区前 10 名优势行业 RCA 均 大于 10 , 涵盖电气机械制造、家具制造、非金属矿物
制造与通用设备制造等行业，呈现扁平分散化的产 业发展模式(表 5)。地区主导产业是属于电气机械 制造行业下的家用空调制造业, 比较优势 RCA 高达 76.98 , 远超其他行业。北深镇以生产家用空调、㕌 房与洁具等家用电器为主, 与行业内的电动机制 造、发电机制造与绝缘品制造等共同构成了全国著 名的家用电器集群。

金融危机后,2013 年地区制造业发展受到重 创,地区龙头企业美的集团通过垂直一体化策略,纵 向延伸整合产业链,布局智能家电、智能制造的发展 战略, 引人工业机器人制造、自动化分拣与仓储运输 系统, 成功向高端化专业化生产升级转型, 带动并衍 生了本地中小家电企业的发展, 极大提升了该行业 比较优势。以美的集团为核心的家电产业集群,推 动地区家用空调行业的迅速发展, 家用空调行业 RCA 高达 100.89, 相比之下, 其他行业优势较 2008 年均大幅降低,地区比较优势 RCA 大于 10 的行业 仅有 5 个(表 6)。地区优势行业的 RCA 核密度分布 显示(图 4),2013年制造业行业优势分布相对更为集 中, 前 10 大优势行业的 RCA 分布标准差(28.87)大大 高于 2008 年(18.99)。这反映了地区行业发展差距 增大、龙头行业呈现“强者更强”的特征,地区产业集 群转向更为高端专业化的生产模式。

可见, 北深镇家电产业集群发展模式的演化过 程, 从微观视角验证了本地行业间产业联系降低、 行业内产业联系增强的现象。

\section{2 产业联系演化的机制探讨}

(1) 宏观全球市场的影响:企业向区域外寻求 更多合作,导致行业间的产业联系降低

大型企业是珠三角城镇发展的主导力量, 为应 对后危机时代弹性生产模式下全球市场对高质量

表 52008 年佛山市北涳镇 RCA 排名前 10 位的行业

Tab.5 Top 10 industries with the largest relative comparative advantage in Beijiao Town, 2008

\begin{tabular}{ccll}
\hline 行业编码 & 比较优势(RCA) & \multicolumn{1}{c}{ 小类产业 } & 所属大类行业 \\
\hline 3952 & 76.98 & 电机械制造 \\
2140 & 25.75 & 家空气调节器制造 & 家具制造 \\
1369 & 25.39 & 其他水产品加工 & 农副食品加工 \\
3129 & 25.30 & 其他水泥制品制造 & 非金属矿物制造 \\
3912 & 21.91 & 电动机制造 & 电气机械制造 \\
3573 & 21.52 & 制冷、空调设备制造 & 通用设备制造 \\
4020 & 19.59 & 雷达及配套设备制造 & 电气机械制造 \\
3954 & 13.45 & 家用厨房电器具制造 & 电气机械制造 \\
3953 & 12.67 & 家用通风电器具制造 & 家具制造业 \\
2130 & 10.61 & 金属家具制造 &
\end{tabular}


表 62013 年北滘镇 RCA 排名前 10 的行业

Tab.6 Top 10 industries with the largest relative comparative advantage in Beijiao Town, 2013

\begin{tabular}{ccll}
\hline 行业小类编码 & \multicolumn{1}{c}{ 小类产业 } & \multicolumn{1}{c}{ 所属大类行业 } \\
\hline 3952 & 100.89 & 家用空气调节器制造 $(\mathrm{RCA})$ & 气机械制造 \\
3129 & 14.32 & 其他水泥制品制造 & 非金属矿物制造 \\
2140 & 12.45 & 塑料家具制造 & 家具制造 \\
3699 & 10.79 & 其他专用设备制造 & 专用设备制造 \\
1369 & 10.24 & 其他水产品加工 & 农副食品加工 \\
2120 & 9.95 & 竹、藤家具制造 & 家具制造 \\
3922 & 9.78 & 电容器及其配套设备制造 & 电机械制造 \\
3613 & 7.58 & 建筑工程用机械制造 & 专用设备制造 \\
2423 & 7.05 & 训练健身器材制造 & 文教体育制品制造 \\
3953 & 6.51 & 家用通风电器具制造 & 电气机械制造
\end{tabular}

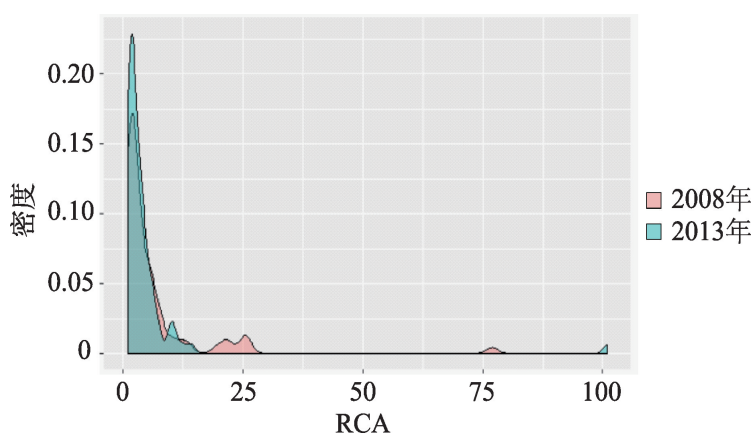

图 4 北滘镇优势行业的 RCA 密度分布

Fig.4 Density of manufacturing industries with comparative advantage in Beijiao Town

产品的需求, 北浫镇以美的集团龙头企业为代表， 与海内外知名企业合作,加大研发投人提高生产制 造技术, 打造自动化生产线下的高端专业化智能家 电设备, 明显减少了家电行业与本地内其他行业中 小企业的合作联系(图 5), 推动地区从传统的扩张式
发展 ${ }^{[43]}$ 转向高端专业模式,强化了当地与区域外的 联系,使得本地生产网络不同行业间的产业联系 变弱。

(2) 中观区域的发展合作: 周边区域发展竞合 格局的倒逼,弱化了行业间的产业联系

家电制造业还与其他行业存在一定的关联, 如 属于有色金属冶炼加工行业的贵金属压延、属于通 用设备制造行业的金属成形机床制造, 以及属于通 信设备计算机行业的雷达配套设备制造等行业(图 5)。其中广州市东涌镇以贵金属加工为主导产业, 佛山市陈村镇以金属成形机床制造为主导产业, 深 圳市坪地街道以雷达配套设备制造为主导产业,相 比以上区域, 北浫镇在这些行业的发展明显处于劣 势。金融危机背景下, 来自资金成本导向、劳动力 用工荒以及高质量需求市场的多重压力,使得北涳 镇企业更愿意与周边区域实现错位竞争, 发展本地 主导家电产业,行业外的相关配套倾向于跳出当地

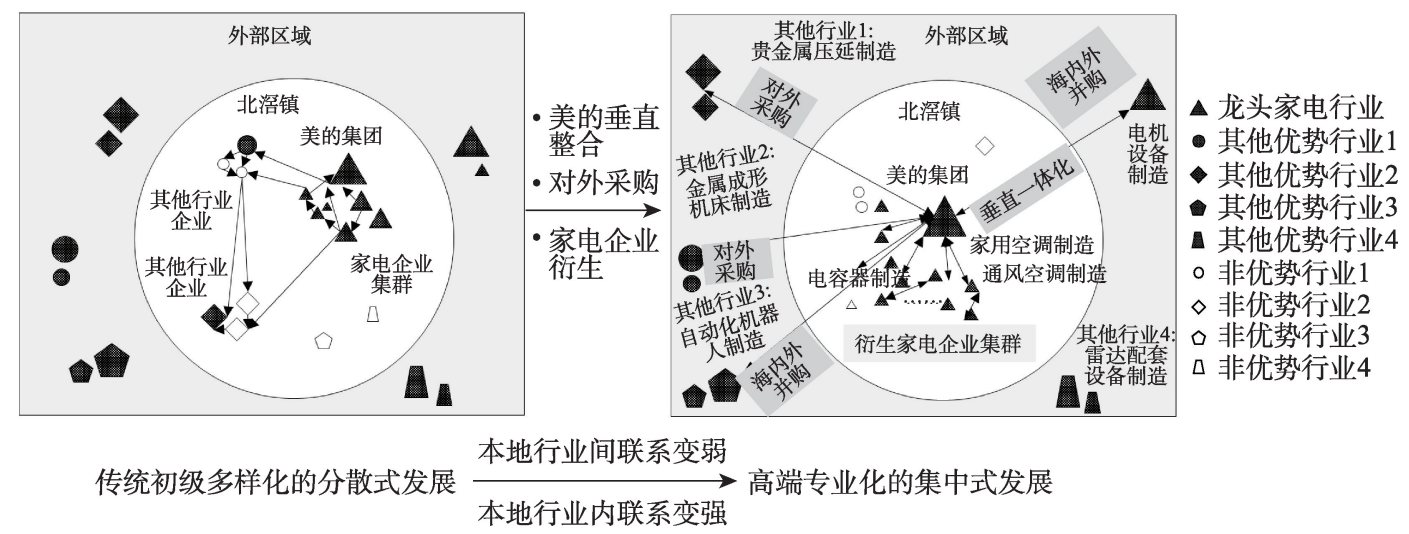

注:图中行业图形大小表示优势程度大小。

图 5 珠三角北深镇生产网络下产业联系演化模式

Fig.5 Pattern of change of industrial proximity under the production network of Beijiao Town in the Pearl River Delta 
向其他地区寻求协作(图 5), 促使了本地内家电行业 与其他行业间的产业联系变弱。

(3) 微观企业选择的影响: 美的集团采取垂直 整合策略, 增强了行业内的产业联系

金融危机后传统家电行业的增长红利势微, 地 区大量配套企业的倒闭对美的集团的供应链配套 造成了冲击。为增强企业韧性,美的集团开始在企 业内部进行垂直整合以寻求突围, 基于传统生产基 础在全球范围内并购先进电机设备制造、工业机器 人制造、系统控制技术等领域的国际大企业, 拓展 自动化生产、物流配送与工业服务等环节, 纵向延 伸完善产业链, 最大化实现生产在企业内的配套供 给, 增强了与行业内本地衍生企业的生产联系(图 5)。近年来, 美的集团的机器人自动化系统业务营 收占总营收比重约 $10 \%$, 反映了美的集团垂直一体 化策略的成功。

(4) 政府手段的干预: 本地政府政策调控推动 产业集群发展,促进行业内的产业联系增强

金融危机背景下, 各级政府大力扶植北深镇的 家电制造行业, 不仅出台《北滘镇促进产业转型升 级指导意见》《北深镇总部商务区招商奖励办法》等 相关政策, 并且每年投人 1200 万元扶持优质工业企 业, 加大对科研投人的支持, 引人国内外知名家电 企业,引导建立健全与完善家电产业链, 助力地区 家电产业的转型升级, 推动了北浫镇家电行业朝着 高端专业的集中式产业集群发展, 促进本地家电行 业内的产业联系增强。

珠三角北深镇生产网络下产业联系演化模式 图(图 5)能有力阐释北深镇的产业联系演化过程, 反 映了传统生产网络下北深镇以美的集团为龙头形 成了家电行业集群, 相关配套主要在本地区域内完 成, 形成初级多样化的分散式发展模式。金融危机 背景下, 一方面, 美的集团的垂直整合策略促进行 业内企业衍生, 增强了本地内产业联系; 另一方面, 北滘家电行业向周边区域寻求贵金属压延制造、金 属成形机床制造与自动化机器人制造等相关行业 的配套协作, 在加强与区域外合作的同时间接降低 了本地行业间的产业联系, 推动本地向高端专业化 的集中式发展演化。

\section{6 结论}

研究通过构建 2008 年与 2013 年的广东省行业
空间网络,对金融危机背景下珠三角的产业演化模 式与机制进行了研究。结果发现, 金融危机背景 下,珠三角行业空间网络发生了显著变化。第一, 表现为行业间产业联系的降低。主要原因在于珠 三角专业镇主导行业为增加韧性、满足弹性生产下 市场对高质量产品的需求, 开始跳出本地生产网 络, 转向区域外寻求配套协作, 强化了地区与其他 地区的联系, 导致本地行业间的产业联系减弱。第 二, 表现为行业内产业联系的增强。专业镇龙头企 业选择垂直整合策略, 纵向延伸完善产业链, 减少 了对外部的依赖,增强了与地区行业内衍生企业的 联系,再加上政府对本地产业集群内企业的干预支 持, 进一步强化了本地行业内的产业联系。这在空 间上体现为专业镇产业集群从扁平多样的分散化 发展模式演化为高端专业化的集中式发展模式,珠 三角呈现出差异化专业镇的产业经济生态。

从行业空间网络的演化过程可以看出,珠三角 正在从多元化的初级加工制造向专业化的高端制 造转型升级。未来,珠三角应持续发力, 注重全球 经济市场与地方产业环境的共同作用,在微观尺度 上, 企业鼓励以技术驱动为导向, 加大研发投人、引 进高技能人才, 加强创新; 在中观尺度上, 专业镇地 方政府应在政策扶持、人才福利、科研创新等方面 对当地主导行业予以积极引导与支持, 推动专业镇 打造特色化的自主高端品牌,增强地区产业集群的 经济韧性; 在区域尺度上,还需要加强珠三角不同 区域间专业镇的协作, 实现专业镇产业集群之间相 互支撑与配套协作。

\section{参考文献(References)}

[1] 马海涛, 刘志高. 地方生产网络空间结构演化过程与机 制研究: 以潮汕纺织服装行业为例 [J]. 地理科学, 2012, 32(3): 308-313. [Ma Haitao, Liu Zhigao. Spatial structure evolutionary process and mechanisms of local production networks: A case study of Chaoshan region in Southeast China. Scientia Geographica Sinica, 2012, 32(3): 308313. ]

[2] 苗长虹. 全球一地方联结与产业集群的技术学习: 以河 南许昌发制品产业为例 [J]. 地理学报, 2006, 61(4): 425434. [Miao Changhong. Global- local nexus and technological learning in industrial cluster: A case study of hairgoods industry in Xuchang, Henan Province. Acta Geographica Sinica, 2006, 61(4): 425-434. ]

[3] 赵哲, 陈烨, 吴钢. 美国金融危机对全球贸易网络影响的 测度研究 [J]. 宏观经济研究, 2016(2): 150-159. [Zhao 
Zhe, Chen Ye, Wu Gang. Research on the impact of the US financial crisis on the global trade network. Macroeconomics, 2016(2): 150-159. ]

[4] 陈肖飞, 郭建峰, 胡志强, 等. 汽车产业集群网络演化与 驱动机制研究: 以奇瑞汽车集群为例 [J]. 地理科学, 2019, 39(3): 467-476. [Chen Xiaofei, Guo Jianfeng, Hu Zhiqiang, et al. The evolution process and driving mechanism of automobile industrial cluster network: Taking Chery Cluster as an example. Scientia Geographica Sinica, 2019, 39(3): 467-476. ]

[5] Glückler J. Economic geography and the evolution of networks [J]. Journal of Economic Geography, 2007, 7(5): 619-634.

[6] 李狍. 珠江三角洲城市间竞争的模式探讨 [J]. 广东社会 科学, 2002(4): 24-29. [Li Xun. Discussion on the mode of competition among cities in the Pearl River Delta. Social Sciences in Guangdong, 2002(4): 24-29. ]

[7] Porter M E. Clusters and the new economics of competition $[\mathrm{M}] / /$ Porter M E. On competition. Boston, USA: Harvard Business School Press, 1998.

[8] Marshall A, Marshall M P. The economics of industry [M]. 2nd Edition. London, UK: Macmillan \& Co., 1920.

[9] 田明, 樊杰. 新产业区的形成机制及其与传统空间组织 理论的关系 [J]. 地理科学进展, 2003, 22(2): 186-194. [Tian Ming, Fan Jie. New industrial districts' developmental mechanism and comparative analysis to traditional spatial organization theories. Progress in Geography, 2003, 22 (2): 186-194. ]

[10] Ernst D, Kim L. Global production networks, knowledge diffusion, and local capability formation [J]. Research Policy, 2002, 31(8/9): 1417-1429.

[11] Henderson J, Dicken P, Hess M, et al. Global production networks and the analysis of economic development $[\mathrm{J}]$. Review of International Political Economy, 2002, 9(3): 436-464.

[12] Krugman P, Elizondo R L. Trade policy and the Third World metropolis [J]. Journal of Development Economics, 1996, 49(1): 137-150.

[13] 贺灿飞, 潘峰华, 孙蕾. 中国制造业的地理集聚与形成 机制 [J]. 地理学报, 2007, 62(12):1253-1264. [He Canfei, Pan Fenghua, Sun Lei. Geographical concentration of manufacturing industries in China. Acta Geographica Sinica, 2007, 62(12): 1253-1264. ]

[14] Hidalgo C A, Klinger B, Barabási A L, et al. The product space conditions the development of nations [J]. Science, 2007, 317: 482-487.

[15] Boschma R, Martin R. Editorial: Constructing an evolutionary economic geography $[\mathrm{J}]$. Journal of Economic
Geography, 2007, 7(5): 537-548.

[16] 苗长虹, 魏也华, 吕拉昌. 新经济地理学 [M]. 北京: 科 学出版社, 2011. [Miao Changhong, Wei Yehua, Lv Lachang. New economic geographies. Beijing, China: Science Press, 2011. ]

[17] 吴加伟, 袁丰, 吕卫国, 等. 金融危机下泛长三角 FDI 时 空格局演化及其机制研究 [J]. 地理科学进展, 2014, 33 (12): 1601-1613. [Wu Jiawei, Yuan Feng, Lv Weiguo, et al. Spatiotemporal change of foreign direct investment and mechanism in the Pan-Yangtze River Delta area under the global financial crisis. Progress in Geography, 2014, 33(12): 1601-1613. ]

[18] 尹贻梅, 刘志高, 刘卫东. 路径依赖理论及其地方经济 发展隐喻 [J]. 地理研究, 2012, 31(5): 782-791. [Yin Yimei, Liu Zhigao, Liu Weidong. Path-dependence and its implication for regional development. Geographical Research, 2012, 31(5): 782-791. ]

[19] Li S, Li X, Chen H H, et al. China's export evolution in the dynamic global product space from 2000 to 2011 [J]. Current Science, 2019, 117(3): 470-479.

[20] Boschma R A, Wenting R. The spatial evolution of the British automobile industry: Does location matter? [J] Industrial and Corporate Change, 2007, 16(2): 213-238.

[21] Maskell P, Malmberg A. Myopia, knowledge development and cluster evolution [J]. Journal of Economic Geography, 2007, 7(5): 603-618.

[22] Neffke F M H, Henning M, Boschma R. The impact of aging and technological relatedness on agglomeration externalities: A survival analysis [J]. Journal of Economic Geography, 2012, 12(2): 485-517.

[23] Martin R, Sunley P. Path dependence and regional economic evolution [J]. Journal of Economic Geography, 2006, 6(4): 395-437.

[24] Rigby D L, Essletzbichler J. Evolution, process variety, and regional trajectories of technological change in US manufacturing [J]. Economic Geography, 1997, 73(3): 269-284

[25] Boschma R A, Lambooy J G. Evolutionary economics and economic geography $[\mathrm{J}]$. Journal of Evolutionary Economics, 1999, 9(4): 411-429.

[26] Bathelt H, Boggs J S. Toward a reconceptualization of regional development paths: Is Leipzig's media cluster a continuation of or a rupture with the past? [J]. Economic Geography, 2003, 79(3): 265-293.

[27] Boschma R A, Frenken K. Why is economic geography not an evolutionary science? Towards an evolutionary economic geography [J]. Journal of Economic Geography, 2006, 6(3): 273-302. 
[28] 颜燕, 贺灿飞, 王俊松. 产业关联、制度环境与区域产业 演化 [J]. 北京工商大学学报(社会科学版), 2017, 32(1): 118-126. [Yan Yan, He Canfei, Wang Junsong. Industrial linkage, institutional environment and regional industrial evolution. Journal of Beijing Technology and Business University (Social Sciences), 2017, 32(1): 118-126. ]

[29] Boschma R, Martin R. The handbook of evolutionary economic geography $[\mathrm{M}]$. Cheltenham, UK: Edward Elgar Publishing, 2010.

[30] Martin R, Sunley P. The place of path dependence in an evolutionary perspective on the economic landscape [M]// Boschma R, Martin R. The handbook of evolutionary economic geography. Chichester, UK: Edward Elgar, 2010.

[31] 李海东, 林志扬. 组织结构变革中的路径依赖与路径创 造机制研究: 以联想集团为例 [J]. 管理学报, 2012, 9 (8): 1135-1146. [Li Haidong, Lin Zhiyang. Mechanism of path dependence and path creation in organizational structure change: The case of Lenovo Group. Chinese Journal of Management, 2012, 9(8): 1135-1146. ]

[32] Boschma R, Coenen L, Frenken K, et al. Towards a theory of regional diversification: Combining insights from evolutionary economic geography and transition studies [J]. Regional Studies, 2017, 51(1): 31-45.

[33] Hausmann R, Klinger B. The structure of the product space and the evolution of comparative advantage [R]. Center for International Development of Harvard University Working Paper Series No.146. Cambridge, USA: Harvard University, 2007.

[34] 宋吉涛, 赵晖, 陆军, 等. 基于投人产出理论的城市群产 业空间联系 [J]. 地理科学进展, 2009, 28(6): 932-943. [Song Jitao, Zhao Hui, Lu Jun, et al. Approach and empirical research on industry contact in urban agglomeration. Progress in Geography, 2009, 28(6): 932-943. ]

[35] 孙露, 薛冰, 耿涌, 等. 基于投人产出表和社会网络分析 的区域产业结构比较分析: 以华东七省(市)为例 [J]. 华 东师范大学学报(自然科学版), 2015(1): 224-233. [Sun $\mathrm{Lu}$, Xue Bing, Geng Yong, et al. Analysis on regional industries based on input-output table and SNA: A case of seven provinces in Eastern China. Journal of East China Normal University (Natural Sciences), 2015(1): 224-233. ]
[36] Hausmann R, Klinger B. South Africa's export predicament [J]. Economics of Transition, 2008, 16(4): 609-637.

[37] Hidalgo C A. The dynamics of economic complexity and the product space over a 42 year period [R]. Center for International Development of Harvard University Working Paper No. 189. Cambridge, USA: Harvard University, 2009.

[38] 张卓颖, 石敏俊. 中国省区间产业内贸易与产业结构同 构分析 [J]. 地理学报, 2011, 66(6): 732-740. [Zhang Zhuoying, Shi Minjun. Intra-industrial trade and interregional structural isomorphism of manufacturing industry based on China- IRIO2002. Acta Geographica Sinica, 2011, 66(6): 732-740. ]

[39] 王茂军, 杨雪春. 四川省制造产业关联网络的结构特征 分析 [J]. 地理学报, 2011, 66(2): 212-222. [Wang Maojun, Yang Xuechun. The structural features of regional manufacturing industrial association network: A case study of Sichuan Province. Acta Geographica Sinica, 2011, 66(2): 212-222. ]

[40] Leman E. Can the Pearl River Delta region still compete? [J]. China Business Review, 2003, 30(3): 6-17.

[41] 吕朝风, 朱丹丹. 中国垂直一体化生产模式的决定因 素: 基于金融发展和不完全契约视角的实证分析 $[\mathrm{J}]$. 中 国工业经济, 2016(3): 68-82. [Lv Chaofeng, Zhu Dandan. Determinants of vertical integration in China industry: An empirical study from financial development and incomplete contract. China Industrial Economics, 2016 (3): 68-82.]

[42] 杜志威, 金利霞, 刘秋华. 产业多样化、创新与经济韧 性: 基于后危机时期珠三角的实证 [J]. 热带地理, 2019, 39(2): 170-179. [Du Zhiwei, Jin Lixia, Liu Qiuhua. Industrial diversity, innovation, and economic resilience: Empirical analysis of the Pearl River Delta in the post- financial crisis era. Tropical Geography, 2019, 39 (2): 170-179. ]

[43] 杜宁, 赵民. 发达地区乡镇产业集群与小城镇互动发展 研究 [J]. 国际城市规划, 2011, 26(1): 28-36. [Du Ning, Zhao Min. On the interactive development between rural industrial clusters and townships in coastal provinces of China. Urban Planning International, 2011, 26(1): 2836. ] 


\title{
Study on the industrial evolution pattern and mechanism of the Pearl River Delta under the background of financial crisis: Based on the perspective of industry space network
}

\author{
LI Shan, SONG Yuru, QIN Xiaozhen, XU Weipan, LI Xun* \\ (School of Geography and Planning, China Regional Coordinated Development and Rural Construction Institute, \\ Urbanization Institute, Sun Yat-sen University, Guangzhou 510275, China)
}

\begin{abstract}
The financial crisis in 2008 had a great impact on the global manufacturing industry, especially on the industrial chains in the "world processing plant" Pearl River Delta region. In the context of the financial crisis, high-quality market demand and flexible production models have impacted the traditional production pattern of the Pearl River Delta. The closure of mass production enterprises has affected the relationship between industrial clusters in the Pearl River Delta. Based on the complex network theory of evolutionary economic geography, this study used the second National Economic Census databases of 2008 and the third National Economic Census databases of 2013 to map the manufacturing industry space network in Guangdong Province at the town and township scale. We analyzed the internal and external relationships of the five leading regional industrial groups. We also discussed their change in the industry space and finally took Beijiao Town of Foshan City as a case study. This study found that the internal industrial proximities within the leading industrial groups increased and the proximities between them decreased in the industry space network. It indicates that the region is beginning to grow out of local support and is more deeply integrated into the external production network, so as to enhance regional resilience and adapt to the new needs of the global market. This reveals that the industries have evolved from a relatively primary, diversified, and decentralized development to a high-end, specialized, and centralized industrial pattern. In the future, the Pearl River Delta urgently needs to transform and respond more quickly to the global market, and it is suggested that the region should not be confined to providing processing and manufacturing functions for developed countries, but strengthen local characteristic production brands and build a complete local industrial chain to achieve sustainable industrial development.
\end{abstract}

Keywords: under the background of financial crisis; industry space network; industrial proximity; evolution; Pearl River Delta 